\title{
Development of Intensity-Duration Frequency Curves for Koforidua City in Ghana
}

\author{
Alexander Fordjour, \\ Research Center of Fluid Machinery Engineering and Technology, Jiangsu \\ University, Zhenjiang, Jiangsu,China, Department of Civil Engineering, \\ Koforidua Technical University, Koforidua, Ghana \\ Anyemedu F.O.A.,
}

Department of Civil Engineering, Kwame Nkrumah University of science and Technology, PMB, Kumasi, Ghana

Frank Owusu Adjei,

Department of Civil Engineering, Koforidua Technical University, Koforidua, Ghana

Ajani A. Ibrahm,

Department of Mechanical Engineering, Koforidua Technical University,

Koforidua, Ghana

Xingye Zhu,

Research Center of Fluid Machinery Engineering and Technology, Jiangsu University, Zhenjiang, Jiangsu, China

Doi: 10.19044/esj.2019.v15n12p82～URL:http://dx.doi.org/10.19044/esj.2019.v15n12p82

\begin{abstract}
The estimation of rainfall intensity for a particular frequency is normally required for design of hydraulic and water resources engineering control structures. The main objective of this paper was to develop IDF curves for Koforidua based on recent rainfall information. Annual Maximum Rainfall depths of various durations over twenty-nine years for Koforidua were obtained from the Ghana Meteorological Services in Accra. Linear regression analysis was used to make the data consistent which allowed for filling in the gaps where data were missing. The data set obtained was then subjected to frequency analysis to determine the distribution which best characterize the data set. The annual maximum series were found to be drawn from the Gumbel distribution whose parameters were computed by fitting the statistics to the data. The Kolmogorov-Smirnov test proves the appropriateness of the fitting. The trend followed the normal Rainfall Intensity-Duration-Frequency-curves. By using easy fit software, Gumbel Extreme type one was found to be the best distribution for the analysis. The results shown that for shorter durations (12 min and $24 \mathrm{~min}$ ), the IDF Curves gave higher intensities for the same return
\end{abstract}


period whiles for longer durations (42min, $1 \mathrm{hr}, 2 \mathrm{hr}, 3 \mathrm{hr}, 6 \mathrm{hr}, 12 \mathrm{hr}$ and 24 $\mathrm{hr}$ ), the IDF Curves gave low intensities for the same return period.The Intensity- Duration-Frequency-Curves obtained for the study area has a general characteristic form of Intensity-Duration-Frequency-Curves. This study could be of significance academic value and useful to improve the hydraulic and water resources engineering.

Keywords: IDF curves, frequency analysis, intensity, Kolmogorov-Smirnov

\section{Introduction}

The most common tool used for planning, designing and operating water resource projects against flood in water resource engineering is the rainfall Intensity-Duration-Frequency relationship curve (Bernard, 1932). Rainfall intensity is expressed as the rate of rainfall in millimeters per hour (Okonkwo and Mbajiorgu, 2010). (Dupont et al., 2000) also defined Rainfall Intensity-Duration-Frequency (IDF) relationships as graphical representations of the amount of water that falls within a given period of time. This relationship is determined through statistical analysis of data from meteorological stations. The IDF presents excellent characteristic to make water resource project design effective. As a result, the IDF technique has been used in many places. For instance, the eastern and northwest part of China have seen many research being carried out to evaluate trends in extreme rainfall at different time scales over the past decade (Wang and Zhou, 2005; Zhu et al.,2018; Zhai et al., 2005) the Korean peninsula, (Baek et al., 2016; Lee et al., 2012; Hua et al., 2018; Seo et al., 2012) Japan, (Kamiguchi et al., 2010), India (Krishnamurthy et al., 2010); the United States (Karl and Knight, 1998; Kunkel et al., 2013b; Melillo et al., 2014) and many parts of the world (Alexander et al., 2006; Frich et al., 2002; Westra et al., 2013a).

Rainfall quantification is generally done using isopluvial maps and Intensity- Duration-Frequency (IDF) curves. The intensity duration frequency formulae are the experimental equations which can be expressed as dependent variable, representing relationship among maximum rainfall intensity as independent variables (Tang et al., 2018; Chow et al.,1988). To demonstrate this, Bell (1969) and Chen (1983) derived the IDF formulae for the United States based on statistical analysis of data. Furthermore, recent progress has been made towards understanding and modelling hourly rainfall intensities internationally, (notably Lenderink and van Meijgaard (2008; Hershfield et al., 1996) for the Netherlands, Kendon et al. (2012) and Chan et al. (2014a, b; 2016)22-24 for the UK, and Sunyer et al. (2017) for Denmark.

Change in climate due to industrialization has been identified as the major cause of global warming. The hydrological cycle has been changed due to the changes in the temperature and precipitation patterns. Projections from 
climate models suggest that the probability of occurrence of intense rainfall in future will increase due to the increase in greenhouse gas emission (Mailhot and Duchesne, 2010; Xu et al., 2018,). Such changes in extreme events have enormous ecological, societal and economic impacts in the form of floods, droughts, heat waves, summer and ice storms and have great implications for municipalities. Design standards at present are based on the historic climate information in the form of IDF curves required level of protection from natural phenomena (Koutsoyiannis et al., 1994; Koutsoyiannis, et al., 1998). However, available information show the city of Koforidua does not have IDF curves, but rely on the IDF curves from Accra for its design. Possible changes may demand new regulations, guidelines for storm water management studies. Revision and update of design practices or retrofitting of existing infrastructure are needed (Prodanovic and Simonovic, 2007; Lu et al., 2018). Therefore, it has become a priority for the city of Koforidua to have a Rainfall IDF curves for effective planning and design of water projects. Hence, the objectives of this paper were: (1) analyze rainfall data to obtain maximum rainfall values of different durations. (2) determine the best probability distribution for the development of IDF curves for Koforidua. (3) develop IDF curves for Koforidua.

\section{Materials and Methods}

\section{Study Area and Sampling Locations}

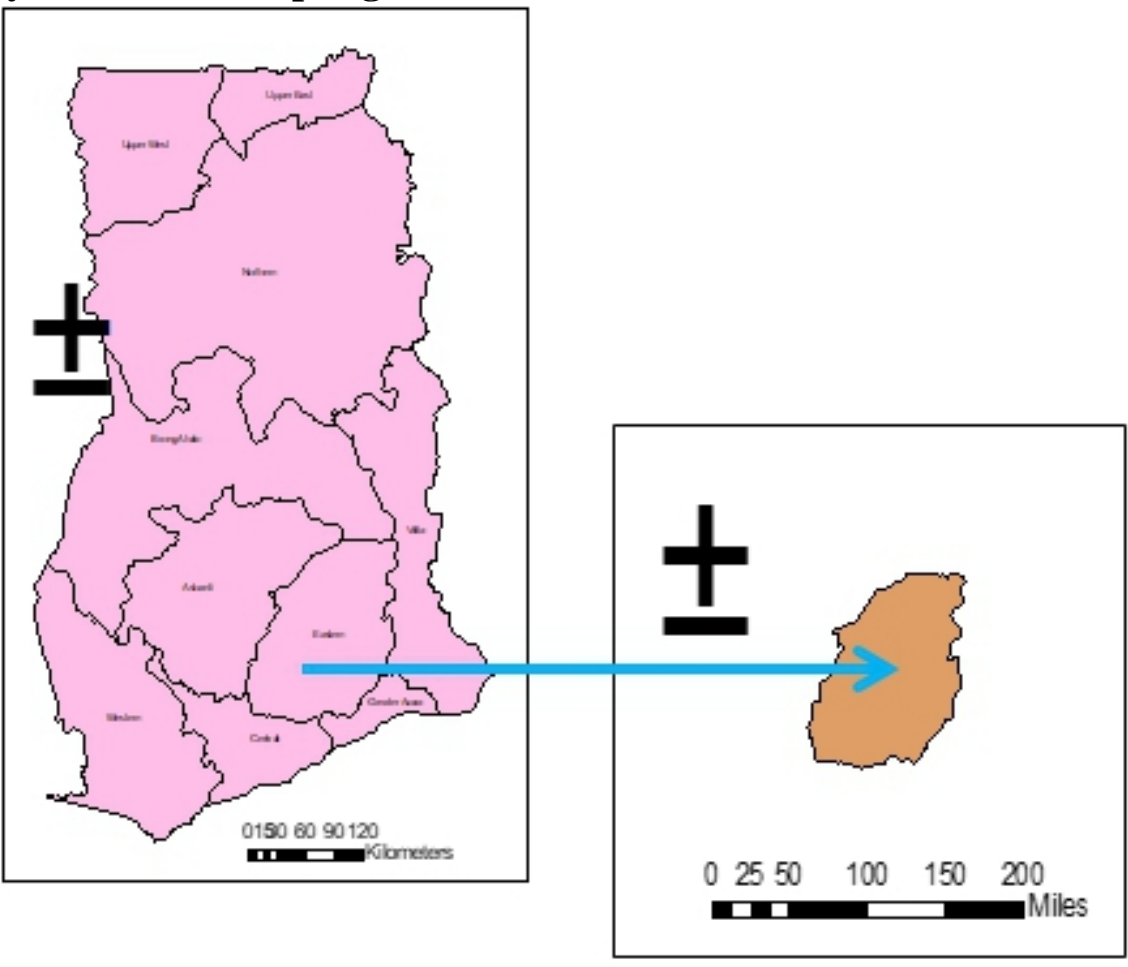


The New Juaben Municipality is one of the Municipalities in the Eastern Region and was established in1988 by the Legislative Instrument (LI) 1426. The Municipality lies between longitudes 10*30'West and 0030 East and latitudes 60 and 70 North. The Municipality shares common boundaries with East-Akim Municipal to the North-East, Akwapim North District to the East and South and Suhum-Kraboa-Coaltar District to the East. It covers a land area of 159 square kilometers representing approximately 0.6 percent of the total surface area of the Eastern Region. It has 52 major communities with Koforidua as its capital. The Municipality is well served with road networks. The Municipality has a road network totaling $72 \mathrm{~km}$ and road density of 0.6 .

\section{Analysis of Rainfall Data}

The data used for this analysis was provided by the Ghana Meteorological Services Department which has the responsibility of measuring, analyzing and storing meteorological data and forecasting the weather in Ghana. The data consists of annual maximum series (AMS) of rainfall depth over a period of twenty-nine years from 1982 to 2011 for nine (9) laps of time: 12min, 24min, 42min, 1hour, 2hours, 3hours, 6hours, 12 hours, and 24 hours. There were missing data in the data provided by Ghana meteorological Services Department, which had to be filled. Also observing the data, it was seen that the 24 min AMS contained less number of missing data and therefore an attempt was made to find the correlation between the 12 min AMS and the rest of the data. When the correlation analysis was performed, it was established that there was a strong correlation between the 42min, $1 \mathrm{hr}$, and $2 \mathrm{hrs}$, 3hrs, 6hrs, $12 \mathrm{hrs}$ and $24 \mathrm{hrs}$ AMS.

\section{Procedure for selecting the appropriate Probability distribution}

Literature review show that, Log Pearson Type III and The Extreme Value type I were the two most appropriate Probability distribution used for IDF curves construction. In order to choose between the two distributions; the following steps were carried out:

For each duration, the Gumbel and Log Pearson Type III distributions were fitted to the Annual Maximum Series using the Easy Fit software. Best of fit for each distribution was determined using Anderson Darling, Chi-square and Kolmogorov- Smirnov test-of-goodness-of-fits at $5 \%$ significance level for each duration.

* After the fitting, both distributions were ranked to determine the appropriateness of the fitting.

* After the analysis, a rank of 1 and 2 were given to the distribution with good fit and less fitting respectively

* After the analysis, Gumbel distribution gave a better fit than the Log Pearson Type III distribution under the following goodness of fit test; 
Chi square, Anderson Daring and Kolmogorov-Smirnov for the nine (9) durations.

* Hence Gumbel distribution was selected for the frequency analysis.

\section{Procedure for Fitting Gumbel distribution to sample data}

The main objective of fitting a statistical distribution to data series is to find out the parameters of the distribution from the sample; and then verify if really the sample are drawn from that statistic. As it has been hypothesized that extreme rainfall events are drawn from Gumbel distribution, the processes describe below show how the fitting is done. After that a statistical test of goodness of fit was performed to assess the validity of the fitting. When the process succeeds, events of very low probability of occurrence or very high return period can be approximated from the distribution.

Step1: Rank AMS values from highest to lowest; assign a rank (m) to each value with the highest value having a rank of (one) and the lowest value a rank of (n). They constitute the observed data.

Step2: Estimate the exceedance probability. The Weibull and Gringorten formula could be used for the estimation of the cumulative probability distribution. The Weibull formula does well and it is exact uniformly distributed population however if the number of observations are limited the Weibull formula performs badly especially at the extremes. This is a major drawback for the Weibull formula.

This is overcome by using Gringorten relation proposed for the estimation of the exceedance of the probability data for limited observation. It is given in Equation below.

$$
P=\frac{m-0.44}{n+0.12}
$$

$p=P(X \geq x) ;$ Note that $p=1-F(x)$

where $F(x)=P(X<x)$

Step 3: Determine the reduced variable from $(\mathrm{p})$ by the formula

$$
U=-\ln [-\ln (1-p)]
$$

Step 4: Compute the sample mean $\left(\mu_{s}\right)$ and standard deviation $\left(\sigma_{s}\right)$; It can easily be done with Excel program.

Step 5: Find the position parameter $\left(\mathrm{x}_{0}\right)$ and the scale parameter $\left({ }^{\mathrm{s}}\right)$ of the Gumbel distribution with the following formulae:

$$
X_{o}=\mu_{s}-\frac{\mu N}{\sigma N} \sigma_{s}
$$


Step 6: use the formulae below to derive the Gumbel mean ${ }^{\mu_{G}}$ and Standard deviation $\sigma_{G}$

$$
\begin{gathered}
\mu_{G}=x_{o}+0.5772 x_{s} \\
\sigma_{G}=1.2825 x_{s}
\end{gathered}
$$

Step 7: for each rank, the Gumbel variable is obtained by use of the formula

$$
X_{G}=X_{o}+\mu x s
$$

They constitute the expected data.

\section{Determination of Annual Rainfall Depth}

Expected Annual Rainfall depth for all the return periods is obtained with the following formula

$$
X_{t}=\mu_{G}+K_{T} X \sigma_{G}(\text { Chow, 1964) }
$$

Where $\mu_{G}$ and $\sigma_{G}$ are Gumbel distribution's mean and standard deviation; and $K_{T}$ is a frequency factor.

$$
K_{T}=-\frac{\sqrt{6}}{\pi}\left\{0.577216+\ln \left[\ln \left(\frac{T}{T-1}\right)\right]\right\}
$$

For return period equal to one year, the formula of $K_{T}$ does not stand and the following formula is used.

$$
K_{t}=-\frac{\sqrt{6}}{\pi} X\left[0.5772-\ln T+\frac{1}{2 X T}+\frac{1}{24 X T^{2}}+\frac{1}{8 X T^{3}}\right]
$$

For $T=5, K_{T}=0.8704$ and the corresponding rainfall depth is equal to $X_{T}$ $=28.38 \mathrm{~mm}$.

\section{Results and Discussion}

\section{Results of Missing data for various duration}

Observing the data, it can been seen that the 24min AMS contained less number of missing data and therefore an attempt was made to find the correlation between the $12 \mathrm{~min}$ AMS and the rest of the data. When the correlation analysis was performed, it was established that there was a strong correlation between the $42 \mathrm{~min}, 1 \mathrm{hr}$, and $2 \mathrm{hrs}$, 3hrs, $6 \mathrm{hrs}, 12 \mathrm{hrs}$ and $24 \mathrm{hrs}$ 
AMS. Table 1, 2 and Fig.1. indicate the breakdown of the missing data, correlation and scatter diagram.

Table 1. Summary of Missing data for various duration

\begin{tabular}{|c|c|}
\hline Duration of Rainfall & No. of missing data \\
\hline $0.2 \mathrm{~min}$ & 35 \\
\hline $0.4 \mathrm{~min}$ & 7 \\
\hline $0.7 \mathrm{~min}$ & 24 \\
\hline $1.0 \mathrm{hr}$ & 40 \\
\hline $2.0 \mathrm{hrs}$ & 38 \\
\hline $3.0 \mathrm{hrs}$ & 39 \\
\hline $6.0 \mathrm{hrs}$ & 61 \\
\hline $12.0 \mathrm{hrs}$ & 71 \\
\hline $24.0 \mathrm{hrs}$ & 92 \\
\hline
\end{tabular}

Table 2. Summary of Correlation for various time intervals

\begin{tabular}{|c|c|c|c|c|c|c|c|c|c|}
\hline & \multicolumn{10}{|c|}{ Time interval (hour) } \\
\hline (hr) & 0.2 & 0.4 & 0.7 & 1 & 2 & 3 & 6 & 12 & 24 \\
\hline 0.2 & 1.000 & 0.584 & 0.533 & 0.422 & 0.321 & 0.262 & 0.234 & 0.214 & 0.166 \\
\hline 0.4 & 0.584 & 1.000 & 0.774 & 0.709 & 0.497 & 0.389 & 0.413 & 0.399 & 0.357 \\
\hline 0.7 & 0.533 & 0.774 & 1.000 & 0.902 & 0.704 & 0.564 & 0.492 & 0.495 & 0.409 \\
\hline 1 & 0.422 & 0.709 & 0.902 & 1.000 & 0.810 & 0.715 & 0.560 & 0.602 & 0.648 \\
\hline 2 & 0.321 & 0.497 & 0.704 & 0.810 & 1.000 & 0.974 & 0.931 & 0.912 & 0.884 \\
\hline 3 & 0.262 & 0.389 & 0.564 & 0.715 & 0.974 & 1.000 & 0.971 & 0.960 & 0.937 \\
\hline 6 & 0.234 & 0.413 & 0.492 & 0.560 & 0.931 & 0.971 & 1.000 & 0.986 & 0.954 \\
\hline 12 & 0.214 & 0.399 & 0.495 & 0.602 & 0.912 & 0.960 & 0.986 & 1.000 & 0.985 \\
\hline 24 & 0.166 & 0.357 & 0.409 & 0.648 & 0.884 & 0.937 & 0.954 & 0.985 & 1.000 \\
\hline
\end{tabular}

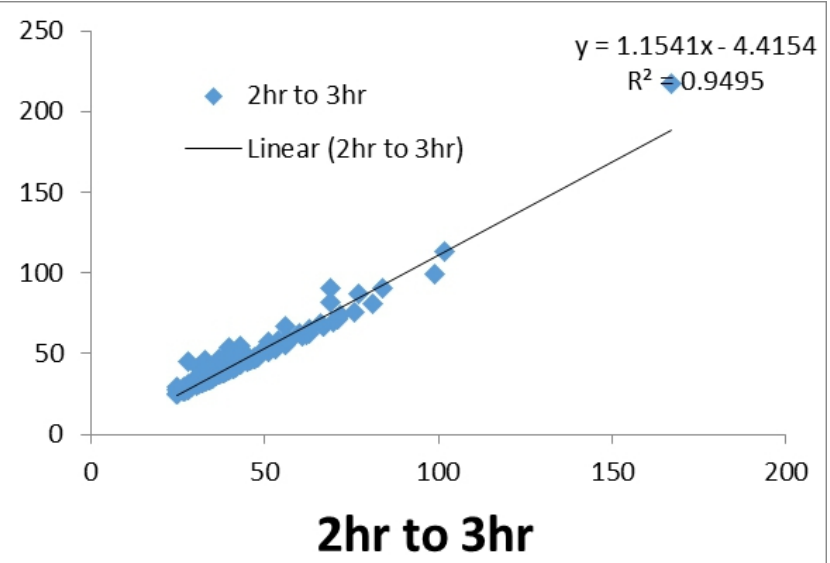

Fig 1. shows scatter diagram various duration

\section{Results of Probability Distribution for all Durations}

Fitting the Anderson darling, Chi-square and KolmogorovSmirnov tests of goodness of fits to Gumbel and Log Pearson Type III 
distributions for $12 \mathrm{~min}(0.2 \mathrm{hr})$ duration, the following results were obtained as shown in Table 4 below. Gumbel distribution provided a better fit than the Log Pearson Type III distribution under the following goodness of fit test; Chi square, Anderson Daring and Kolmogorov-Smirnov for the nine (9) durations. Hence Gumbel distribution was selected for the frequency analysis.

Table 3. Ranking for Gumbel and Log Pearson Type III for the Nine Durations

\begin{tabular}{|c|c|c|c|c|c|c|}
\hline \multirow{2}{*}{$\begin{array}{c}\text { DURATION } \\
\text { Hours }\end{array}$} & \multicolumn{6}{|c|}{ RANK } \\
\cline { 2 - 7 } & \multicolumn{2}{|c|}{ K S } & \multicolumn{2}{c|}{ AD } & \multicolumn{2}{c|}{ CS } \\
\cline { 2 - 7 } & EVI & LP3 & EVI & LP3 & EVI & LP3 \\
\hline 0.20 & 1 & 2 & 1 & 2 & N/A & N/A \\
\hline 0.40 & 1 & 2 & 1 & 2 & 2 & 1 \\
\hline 0.7 & 1 & 2 & 1 & 2 & 1 & 2 \\
\hline 1.0 & 1 & 2 & 1 & 2 & 1 & 2 \\
\hline 2.0 & 1 & 2 & 1 & 2 & 2 & 1 \\
\hline 3.0 & 1 & 2 & 1 & 2 & 1 & 2 \\
\hline 6.0 & 1 & 2 & 1 & 2 & 1 & N/A \\
\hline 12 & 1 & 2 & 1 & 2 & 1 & 1 \\
\hline 24 & 1 & 2 & 1 & 2 & 1 & N/A \\
\hline
\end{tabular}

KS:Kolmogorov-Smirnov, AD: Anderson Daring CS: Chi square, EVI: Gumbel distribution and LP3: Log Pearson Type III distributions

\section{Results for testing the null hypothesis if the data were extracted from the Gumbel Distribution}

Tables 4. shows the tests- of- goodness-of-fit done on the measured data using chi-square test. After the analysis eight of the durations were confirmed to be drawn from a Gumbel distribution whiles one of them was not with four degree of freedom (Anderson and Darling,(1954). Using a 5\% significance level, if the value is less or equal to $5 \%$ significance level than we assume that the observation is drawn from a Gumble distribution. Since $8.42 \leq 9.488$, the hypothesis that the annual data is drawn from a Gumbel distribution is accepted.

Table 4. Chi-square

\begin{tabular}{|c|c|c|c|c|r|}
\hline test $(0.4$ hr analysis $)$ & & & & & \\
\hline Interval & O- observed data & E-expected & O-E & $(\mathrm{O}-\mathrm{E}) 2$ & \multicolumn{1}{c|}{$(\mathrm{O}-\mathrm{E}) 2 / \mathrm{E}$} \\
\hline $0-30$ & 5 & 8 & -3 & 9 & 1.8 \\
\hline $30-35$ & 7 & 3 & 4 & 16 & 2.2857 \\
\hline $35-40$ & 6 & 3 & 3 & 9 & 1.5 \\
\hline $40-45$ & 6 & 3 & 3 & 9 & 1.5 \\
\hline $45-60$ & 3 & 5 & -2 & 4 & 1.3333 \\
\hline $60-100$ & 2 & 5 & -3 & 9 & 0 \\
\hline$>100$ & 0 & 2 & -2 & 4 & 0 \\
\hline & sum $=29$ & sum $=29$ & & & sum $=8.42$ \\
\hline
\end{tabular}


Table 5. Expected Annual Rainfall depth for all the return periods

\begin{tabular}{|c|c|c|}
\hline $\mathbf{T}(\mathbf{y r s})$ & $\boldsymbol{K}_{\boldsymbol{T}}$ & $X_{T}(\mathrm{~mm})$ \\
\hline $\mathbf{5}$ & 0.8704 & 28.38 \\
\hline $\mathbf{1 0}$ & 1.5478 & 32.65 \\
\hline $\mathbf{1 5}$ & 1.93 & 35.059 \\
\hline $\mathbf{2 0}$ & 2.226 & 36.925 \\
\hline $\mathbf{2 5}$ & 2.4032 & 38.042 \\
\hline $\mathbf{5 0}$ & 3.0384 & 42.047 \\
\hline $\mathbf{1 0 0}$ & 3.6682 & 46.017 \\
\hline
\end{tabular}

\section{Results of Intensity-Duration-Frequency}

Rainfall estimates in $\mathrm{mm}$ and their intensities in $\mathrm{mm} / \mathrm{hr}$ for various return periods were analyzed using Gumbel distribution. Table 6. Presents maximum rainfall intensities at durations of $12 \mathrm{~min}, 24 \mathrm{~min}, 42 \mathrm{~min}, 1 \mathrm{hr}, 2 \mathrm{hrs}$, $3 \mathrm{hrs}, 6 \mathrm{hrs}, 12 \mathrm{hrs}$ and $24 \mathrm{hrs}$ at return periods of 5, 10, 15, 20, 25, 50, and100yr. The IDF curves for Koforidua are shown in Figs 2. and 3. The results shown that for shorter durations(12 $\mathrm{min}$ and $24 \mathrm{~min}$ ), the new IDF Curves gave higher intensities for the same return period whiles for longer durations(42min, $1 \mathrm{hr}, 2 \mathrm{hr}, 3 \mathrm{hr}, 6 \mathrm{hr}, 12 \mathrm{hr}$ and $24 \mathrm{hr}$ ), the new IDF Curves gave low intensities for the same return period. From the results it appears that Rainfall intensities rise in parallel with the rainfall return periods and also for the same return period, high intensities are related to short durations.

Table 6. Estimates of Intensity-Duration-Frequency (complete table)

\begin{tabular}{|c|c|c|c|c|c|c|c|}
\hline & \multicolumn{7}{|c|}{ Return Period (Years) } \\
\hline $\begin{array}{c}\text { Duration } \\
\text { (Hours) }\end{array}$ & 5-Year & 10-Year & 15-Year & 20-Year & 25-Year & 50-Year & 100-Year \\
\hline 0.2 & 141.90 & 163.25 & 175.30 & 184.63 & 190.21 & 210.24 & 230.09 \\
\hline 0.4 & 123.80 & 144.70 & 156.48 & 165.61 & 171.08 & 190.67 & 210.10 \\
\hline 0.7 & 88.77 & 102.10 & 109.62 & 115.44 & 118.93 & 131.42 & 143.81 \\
\hline 1 & 70.37 & 81.06 & 87.10 & 91.77 & 94.57 & 104.60 & 114.54 \\
\hline 2 & 45.26 & 54.37 & 59.52 & 63.50 & 65.88 & 74.44 & 82.91 \\
\hline 3 & 33.79 & 41.63 & 46.05 & 51.53 & 51.53 & 58.88 & 66.17 \\
\hline 6 & 17.64 & 21.56 & 23.77 & 25.48 & 26.51 & 30.18 & 33.82 \\
\hline 12 & 8.89 & 10.88 & 12.01 & 12.88 & 13.40 & 15.28 & 17.13 \\
\hline 24 & 4.58 & 5.62 & 6.21 & 6.66 & 6.93 & 7.91 & 8.87 \\
\hline
\end{tabular}




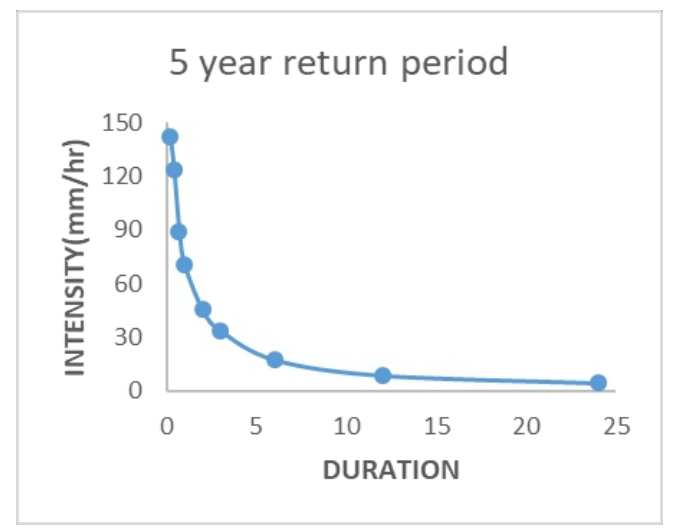

(a)

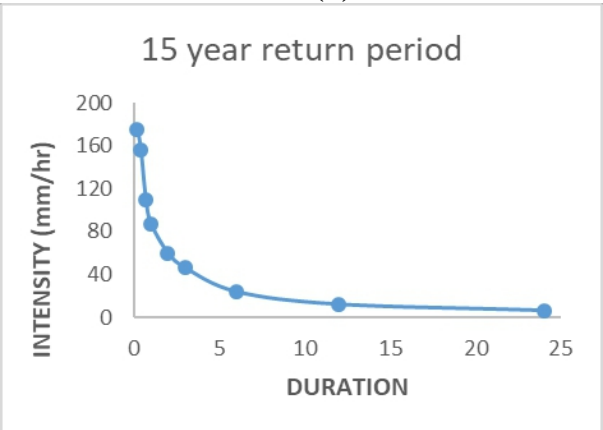

(c)

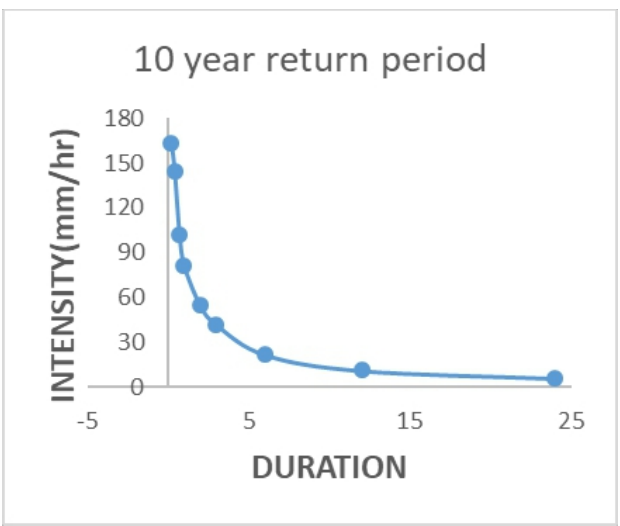

(b)

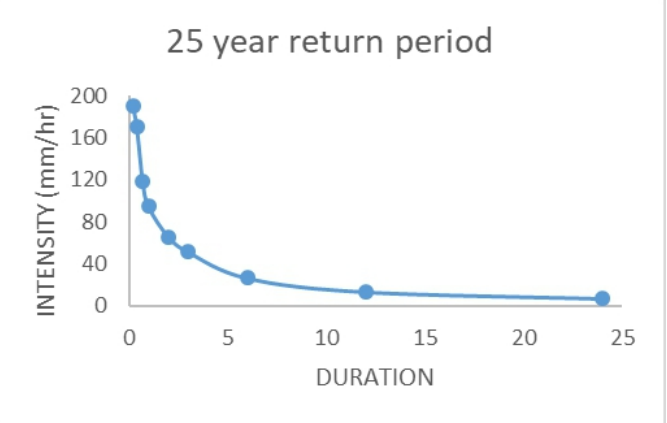

(d)

Fig 2. intensity duration curves of Koforidua city for (a) 5year, (b) 10year, (c) 15 year, and (d) 25 year return periods

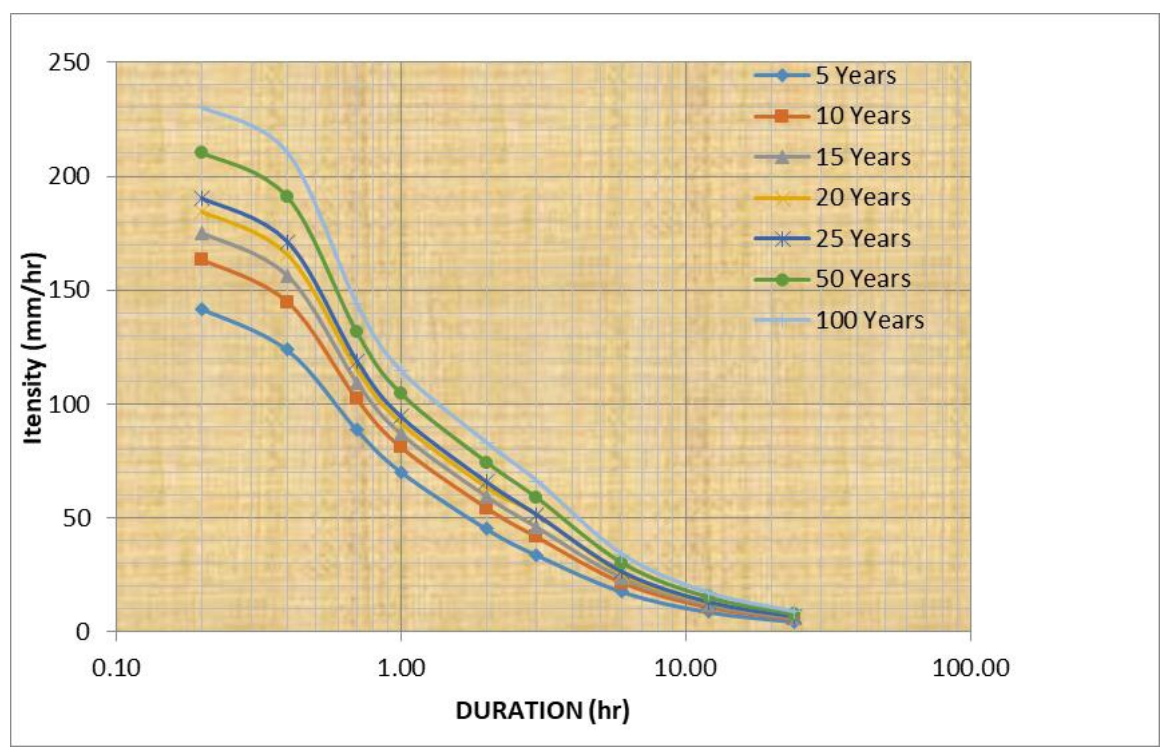

Fig 3. Semi-log IDF Curves for Koforidua 


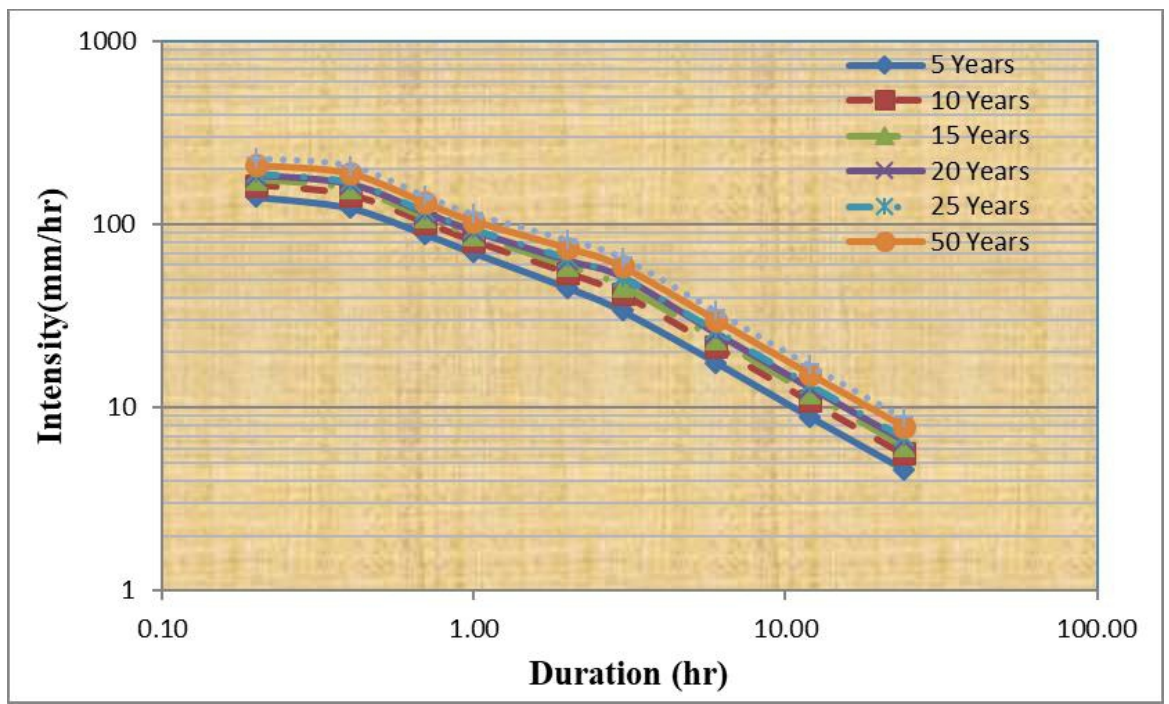

Fig 4. Log-log IDF Curves for Koforidua Ghana

\section{Conclusions}

The study was conducted for the formulation and construction of IDF curves using data from recorded stations. By using easy fit software, Gumbel Extreme type I was found to be the best distribution for the data set. The results shown that for shorter durations(12 $\mathrm{min}$ and $24 \mathrm{~min}$ ), the new IDF Curves gave higher intensities for the same return period whiles for longer durations (42min, $1 \mathrm{hr}, 2 \mathrm{hr}, 3 \mathrm{hr}, 6 \mathrm{hr}, 12 \mathrm{hr}$ and $24 \mathrm{hr}$ ), the new IDF Curves gave low intensities for the same return period. From the results, it appears that Rainfall intensities rise in parallel with the rainfall return periods and also for the same return period, high intensities were related to short durations. The Intensity- Duration-Frequency-Curves obtained for the study area has the general characteristic form of Intensity-Duration-FrequencyCurves.

\section{Acknowledgement}

The authors wish to acknowledge that this research work was founded by the National Key Research and Development Program of China (No. 2016YFC0400202), and the Priority Academic Program Development of Jiangsu Higher Education Institutions (PAPD).

\section{References:}

1. Anderson, T. and Darling, D. (1954). A test of goodness of fit. Journal of the American Statistical Association, 49 :765-769.

2. Alexander, L., Zhang, X., Peterson, T., Caesar, J., Gleason, B., Klein Tank, A., Haylock, M., Collins, D., Trewin, B., Rahimzadeh, F. 
(2006). Global observed changes in daily climate extremes of temperature and precipitation. J. Geophys. Res.: Atmos. 111 (D5).

3. Baek, H.J., Kim, M.K., Kwon, W.T. (2016). Observed short-and longterm changes in summer precipitation over South Korea and their links to large-scale circulation anomalies. Int. J. Climatol.

4. Bell, (1969). Generalized Rainfall Duration Frequency Relationships. Journal of Hydraulic Div. ASCE, 95(1).

5. Bernard, (1932). "Formulas for rainfall intensities of long duration", Transactions, ASCE, 96 (Paper No.1801), 592-624.

6. Chen, (1983)." Rainfall Intensity-Duration-Frequency Formulas. Journal of Hydraulic Engineering, 109 (12).

7. Chow, V.T., Maidment, D.R. and Mays, L.W. (1988), Applied Hydrology, Mc Graw-Hill.

8. Chan, S.C., Kendon, E.J., Fowler, H.J., Blenkinsop, S., Roberts, N.M. (2014a). Projected increases in summer and winter UK sub-daily precipitation extremes from high-resolution regional climate models. Environ. Res. Lett. 9, 84019.

9. Chan, S.C., Kendon, E.J., Fowler, H.J., Blenkinsop, S., Roberts, N.M., Ferro, C.A.T. (2014b). The value of high-resolution met office regional climate models in the simulation of multihourly precipitation extremes. J. Clim. 27, 6155-6174.

10. Chan, S.C., Kendon, E.J., Roberts, N.M., Fowler, H.J., Blenkinsop, S. (2016). Downturn in scaling of UK extreme rainfall with temperature for future hottest days. Nat. Geosci. 9, 24-28. .

11. Chow, V.T.(1964). Handbook of Applied Hydrology, McGraw-Hill, New York.

12. Dupont, B.S. and Allen, D.L. (2000). Revision of the Rainfall Intensity Duration Curves for the Commonwealth of Kentucky. Kentucky Transportation Center, College of Engineering, University of Kentucky, USA.

13. Hershfield, D. M.(1961). Rainfall Frequency Atlas of the United States for Durations From 30 Minutes to 24 hours and Return Periods From 1 to 100 Years, U. S. Weather Bureau Technical Paper 40, Washington, DC, 1961

14. Hua L, Jiang Y, Li H, Zhou X Y.(2018). Hydraulic performance of low pressure sprinkler with special-shaped nozzles. Journal of Drainage and Irrigation Machinery Engineering, 36(11): 1109-1114. (in Chinese)

15. Krishnamurthy, C.K.B., Lall, U., Kwon, H.-H. (2009). Changing frequency and intensity of rainfall extremes over India from 1951 to 2003. J. Clim. 22 (18), 4737-4746 
16. Koutsoyiannis, D. (1994). A Stochastic Disaggregation Method for Design Storm and Flood Synthesis, Journal of Hydrology, 1994.

17. Koutsoyiannis, D., Kozonis., and Manetas, A. (1998). A Mathematical Frame work for Studying Rainfall Intensity-Duration- Frequency Relationships. Journal of Hydrology, 206, (1-2).

18. Kendon, E.J., Roberts, N.M., Senior, C.A., Roberts, M.J. (2012). Realism of rainfall in a very high-resolution regional climate model. J. Clim. 25, 5791-5806. http://dx. doi.org/10.1175/JCLI-D-11-00562.1

19. Kunkel, K.E., Karl, T.R., Brooks, H., Kossin, J., Lawrimore, J.H., Arndt, D., Bosart, L., Changnon, D., Cutter, S.L., Doesken, N. (2013b). Monitoring and understanding trends in extreme storms: State of knowledge. Bull. Am. Meteorol. Soc. 94 (4), 499-514.

20. Kamiguchi, K., Arakawa, O., Kitoh, A., Yatagai, A., Hamada, A., Yasutomi, N.( 2010). Development of APHROJP, the first Japanese high-resolution daily precipitation product for more than 100 years. Hydrol. Res. Lett. 4, 60-64

21. Karl, T.R., Knight, R.W. (1998). Secular trends of precipitation amount, frequency, and intensity in the United States. Bull. Am. Meteorol. Soc. 79 (2), 231-241

22. Llasat, (2010). An objective classification of rainfall events on the basis of their convective features: application to rainfall intensity in the northeast of Spain, International. Journal. of Climatology, 21,10851400 ,

23. Lenderink, G., van Meijgaard, E. (2008). Increase in hourly precipitation extremes beyond expectations from temperature changes. Nat. Geosci. 1, 511-514. http://dx.doi.org/10.1038/ngeo262

24. Lu M Y, Lu K J, Hu G, Zhu X .Y. (2018). Experiment on hydraulic performance of type SD-03 pop-up sprinkler. Journal of Drainage and Irrigation Machinery Engineering, 36(11): 1120-1124. (in Chinese)

25. Min, S.-K., Zhang, X., Zwiers, F.W., Hegerl, G.C. (2011). Human contribution to moreintense precipitation extremes. Nature 470 (7334), 378-381

26. Melillo, J.M., Richmond, T.T., Yohe, G. (2014). Climate Change Impacts in the United States. Third National Climate Assessment

27. Mailhot A., and Duchesne. (2010). Assessment of Future Change in Intensity-Duration-Frequency curves for Southern Quebec using the Canadian Regional Climate Model, Journal of Hydrology,

28. Okonkwo and Mbajiorgu, (2010). Rainfall intensity duration frequency analysis for Southeastern Nigeria. Agric Eng Int: CIGR journal 2010,12 (1): 22-30 
29. Oyebande LEKAN, (1982). Deriving rainfall intensity-durationfrequency relationships and estimates for regions with inadequate data. Hydrological Sciences- Journal-Journaldes Sciences Hydrologiques, vol. 27 , no. 3

30. Rasmussen, P.F., F. Ashkar, D. Rosbjerg, and B. Bobee, (1994). The POT method for flood estimation: a review. In: Hipel, K.W. (Ed.), Stochastic and Statistical Methods in Hydrology and Environmental Engineering, Extreme Values: Floods and Droughts, vol.1Kluwer, Dordrecht, NL, pp. 15-26

31. Rathnam, E.V, Jayakumar, K.V. and Cunnane, C. (2000). Runoff Computation in a Data Scarce Environment for Urban Storm Water Management-A Case Study, Ireland.

32. Stocker, T.F., Qin, D., Plattner, G.-K., Tignor, M., Allen, S.K., Boschung, J., Nauels, A., Xia, Y., Bex, V., Midgley, P.M., 2014. Climate Change (2013): The Physical Science Basis. Cambridge University Press Cambridge, UK, and New York

33. Sunyer, M.A., Luchner, J., Onof, C., Madsen, H., Arnbjerg-Nielsen, K. (2017). Assessing the importance of spatio-temporal RCM resolution when estimating sub-daily extreme precipitation under current and future climate conditions. Int. J. Climatol. 37, 688-705. http://dx.doi.org/10.1002/joc.4733

34. Tang L D, Yuan S Q, Qiu Z P.(2018). Development and research status of water turbine for hose reel irrigator. Journal of Drainage and Irrigation Machinery Engineering, 36(10): 963-968. (in Chinese)

35. Wang, Y., Zhou, L. (2005). Observed trends in extreme precipitation events in China during 1961-2001 and the associated changes in largescale circulation. Geophys. Res. Lett. 32 (9)

36. Westra, S., Alexander, L.V., Zwiers, F.W. (2013a). Global increasing trends in annual maximum daily precipitation. J. Clim. 26 (11), 39043918

37. Xu S R, Wang X K, Xiao S Q, Fan E D, Zhang C X, Xue Z L, Wang X. (2018). Experimental study on double-nozzle jet sprinkler. Journal of Drainage and Irrigation Machinery Engineering, 36(10): 981-984. (in Chinese)

38. Zhai, P., Zhang, X., Wan, H., Pan, X. (2005). Trends in total precipitation and frequency of daily precipitation extremes over China. J. Clim. 18 (7), 1096-1108

39. Zhu X Y, Chikangaise P, Shi W D, Chen W H. Yuan S. Q.(2018). Review of intelligent sprinkler irrigation technologies for remote autonomous system. International Journal of Agricultural and Biological Engineering, 11(1): 23-30. 